\title{
Population development in rice black bug, Scotinophara latiuscula (Breddin), under varying nitrogen in a field experiment
}

\author{
F.G. Horgan ${ }^{1 *}$, Q. Vu²,3,4, C.C. Bernal ${ }^{4}$, A.F. Ramal4,a, J.M. Villegas ${ }^{4, b}$ \\ and M.L.P. Almazan ${ }^{4}$ \\ 1 University of Technology Sydney, 15 Broadway, Ultimo, Sydney NSW 2007, \\ Australia \\ ${ }^{2}$ Cuulong Delta Rice Research Institute, Tan Thanh, Thoi Lai District, Can Tho, \\ Vietnam \\ ${ }^{3}$ Helmholtz Centre for Environmental Research, Theodor-Lieser-Strasse, 06210, \\ Halle, Germany \\ 4 International Rice Research Institute, DAPO Box 7777, Metro Manila, Philippines \\ a Present address: Bioeq Energy Holdings, Magallanes, Cavite 4113, Philippines \\ ${ }^{b}$ Present address: Louisiana State University, Baton Rouge, 70808, USA \\ *Corresponding author: finbarr.horgan@uts.edu.au,f.g.horgan@gmail.com
}

\section{With 5 figures}

\begin{abstract}
The effects of nitrogenous fertilizers on black bug (Hemiptera: Pentatomidae) colonization and population development in rice fields has not been studied previously. This study reports on the distribution of adults, eggs and nymphs of the black bug, Scotinophara latiuscula (Breddin) during a seasonal outbreak in a rice (Oryza sativa L.) yield experiment that varied nitrogen application rates. Plots at the edge of the experimental field had higher black bug densities. Adult distribution was only weakly affected by nitrogen level. Densities of egg-masses and nymphs increased linearly with increasing nitrogen rates. Nymph development was also more advanced under high nitrogen. Oviposition was highest on larger plants with high grain numbers (actively filling grain), but was otherwise unaffected by the varieties in the experiment. Our results indicate that the build-up of black bug populations in rice is influenced by nitrogen fertilizer rates mainly acting on egg-laying and nymph development.
\end{abstract}

Keywords: Field experiment, host plant resistance, nymph, phloem feeding, plant phenology, preference-performance 


\section{Introduction}

Farm management has a significant impact on the damage caused to crops by herbivores and diseases (Vandemeer et al. 1998, Hu et al. 2016, Horgan 2017). In particular, the type of fertilizer used by farmers and the rate and time of fertilizer application have been shown to affect the density and fitness of herbivores across a range of crops (Butler et al. 2012, Hu et al. 2016, Rashid et al. 2016). However, the outcomes of different herbivore-plant interactions often vary across gradients of fertilizer application. This is because fertilizers also affect the host plant, either increasing or decreasing specific plant defenses or altering the plant's tolerance to damage (Rubia-Sanchez et al. 1999, Han et al. 2014, Horgan et al. 2016a, 2016b). Rice (Oryza sativa L.) is vulnerable to attack from a range of herbivores when grown under high nitrogen (de Kraker et al. 2000, Hu et al. 2016). However, rice also has noted tolerance to herbivore damage, particularly during active tillering. In contrast, rice plants attacked by herbivores during later crop stages tend to have higher yield losses (Rubia-Sanchez et al. 1999, Horgan et al. 2016a).

To date, much of the published information on how fertilizers affect rice herbivores has been based on laboratory and greenhouse studies (Horgan \& Crisol 2013). However, studies that use a range of fertilizer levels during experiments with potted plants are prone to underestimate nitrogen effects because of intra-root competition within pots (Crisol et al. 2013). Furthermore, choice studies using potted plants are conducted at a scale that is unrepresentative of field situations. A relatively small number of field studies have examined densities and damage by insect herbivores to rice under gradients of nitrogen application (i.e., de Kraker et al. 2000, Lu et al. 2006, Hu et al. 2016). These have indicated a range of possible responses by different herbivore species to nitrogen application rates. This variety of responses may be partly due to differences in life-history strategies, diets, or feeding physiologies between herbivore species (Gripenberg et al. 2010, Horgan et al. 2016a). Understanding how these different herbivores respond to fertilizer inputs can support holistic approaches to pest management in field crops such as rice (Horgan 2017).

Several species of black bug (Scotinophara spp.: Hemiptera: Pentatomidae) damage rice throughout South and East Asia (Joshi et al. 2007). An increasing occurrence of black bug outbreaks and a rapid expansion in the geographical range of the outbreaks since the early 1970s (Heinrichs et al. 1987, Redondo et al. 2007) suggests that these are Green Revolution pests that respond to high nitrogen. Increased rice cropping intensities and poor synchronization of rice crops in some tropical regions have also been associated with black bug outbreaks (Redondo et al. 2007). Because of their sporadic occurrence and relatively localized outbreaks, black bugs have received little research attention (Joshi et al. 2007). Furthermore, field experiments with black bugs are difficult to plan and execute due to normally low black bug densities. To our knowledge, there have been no studies on the responses by black bugs to rice plants under varying nitrogen applications either in the field or in greenhouses. Furthermore, little information exists on field colonization patterns and population processes during field infestations (Kim et al. 2007). 
In November 2013, an outbreak of the black bug Scotinophara latiuscula (Breddin) occurred in a long-term continuous cropping experiment at the International Rice Research Institute (IRRI) in the Philippines. The black bug S. latiuscula has become increasingly problematic in paddy fields on Luzon Island (Philippines) over the last 10 years. The yield response experiment included a range of rice varieties under four nitrogen regimes in a randomized block design providing a rare opportunity to examine responses by the black bug to host plant quality. We examined changes in the densities of different black bug life stages as a response to the levels of nitrogen applied to the field plots. Because of their relatively broad diets and poor dispersal capacity (Nakasuji et al. 1965, Joshi et al. 2007), we hypothesized that adult black bug densities would respond poorly to variations in host quality, but that nymph densities and development would be greater in the high quality (high nitrogen) field plots. We also assessed the densities of black bugs across the range of rice varieties at the experimental site to assess plant traits that might influence rice susceptibility to black bug damage. Although preliminary in nature, to our knowledge this is the first study on the field ecology of S. latiuscula and the first study to examine responses by any rice black bug species to fertilizer inputs.

\section{$2 \quad$ Materials and methods}

\section{$2.1 \quad$ Study species}

A number of black bug species damage rice in Asia (Joshi et al. 2007). The taxonomy of black bugs is complicated. Several species are endemic to tropical Asia and many occur in the Philippines (Barrion et al. 2007). At least eight species have been recognized on Luzon Island (the most northerly large island of the Philippine Archipelago) of which S. latiuscula is the most widespread. This species is also the principal black bug attacking rice in Laguna Province (Barrion et al. 2007) where the present study was conducted. Black bugs attack rice plants at all crop stages, but especially from maximum tillering to grain ripening (Heinrichs et al. 1987). The females deposit their eggs on the basal portion of the rice plant near the water surface. Eggs are deposited in masses that vary in size between species. For most species the eggs hatch in about 4 days and there are 4-5 instars. Both adults and nymphs remain between tillers at the base of the plant where they suck plant sap. During the tillering stage, they cause stunting of the plants and tiller death, known as 'deadheart'. During panicle development, rice bugs reduce grain filling resulting in panicles with sterile, unfilled grains that are known as 'whiteheads'. Under high densities and particularly during early crop stages, black bugs can kill the rice plants, causing tillers to shrivel and turn yellow-brown, a condition known as 'bugburn' (Morrill et al. 1995). 


\subsection{Study site and field experiment}

The long term continuous cropping experiment (LTCCE) is the longest running rice triple-cropping experiment in the world. The experiment was established in 1963 to examine the sustainability of intensive rice cropping. Details of the experiment are presented by Dobermann et al. (2000). For the purpose of the present paper, we only present details as related to the September-December 2013 crop, which was the 149 th crop produced since the beginning of the experiment.

The 1 ha site is located at IRRI, Los Baños, Philippines $\left(14^{\circ} 11^{\prime} \mathrm{N}, 121^{\circ} 15^{\prime} \mathrm{E}\right.$, $21 \mathrm{~m}$ asl). The soils have a high clay content $(60 \%)$ and $2-4 \%$ organic carbon. The experiment has a split-plot randomized complete block design with nitrogen levels as the main plots $(25 \times 25 \mathrm{~m})$ and varieties as subplots $(6$ subplots of $8.3 \times 8.3 \mathrm{~m}$ in each main plot were planted with different rice varieties) with 4 replicated blocks. . The varieties grown in the subplots were IR09N536, IR06N155, IR07A253, NSIC Rc158, NSIC Rc212 and NSIC Rc222. Each main plot was surrounded by permanent levees (bunds) to limit the movement of water and fertilizer between plots.

Rice was sown to dry seedbeds in August 2013. At 14 days after sowing (DAS) on 3 September 2013 - the seedlings were transplanted to the plots. Hills were planted at a spacing of $25 \times 25 \mathrm{~cm}$. The plots received one of four fertilizer levels: These were $0 \mathrm{~kg} \mathrm{~N} \mathrm{ha}^{-1}, 45 \mathrm{~kg} \mathrm{~N} \mathrm{ha}^{-1}, 90 \mathrm{~kg} \mathrm{~N} \mathrm{ha}^{-1}$ and $135 \mathrm{~kg} \mathrm{~N}^{-1}$ applied in equal measures over 3 application days (7-10 days after transplanting (DAT), 24 DAT and 42 DAT). Plots were treated with molluscicide to control apple snails (Pomacea canaliculata Lamarck) prior to transplanting. In 2013, the fields at IRRI and the adjacent Experiment Station were highly synchronized with a dry season crop from January to June and a wet season crop from July to December (double cropping). However, because it has three crops per year (triple cropping), the LLCCE had a standing crop during November 2013, when much of the surrounding land had already been harvested.

\subsection{Field monitoring}

Rice black bug was noted in the plots in early November 2013. Our sampling was restricted in time and intensity to avoid interfering with the normal protocol and management of the LLCCE and because the infestation occurred late in the crop season. We monitored the populations in the plots by destructively sampling a single rice plant from each subplot in the LTCCE on 8 November 2013. The plants were pulled from the soil with their roots largely intact and rapidly placed in thick plastic bags. On the same day, that plants were examined for black bugs, noting the numbers of adults, egg masses and nymphs and recording development of the eggs (yellow, brown, or black) and nymphs (instar). The numbers of eggs per egg mass were also recorded. Black bug density estimates from destructive sampling correlate well with visual counts from rice plants in situ (i.e, not destructively sampled), indicating that most bugs 

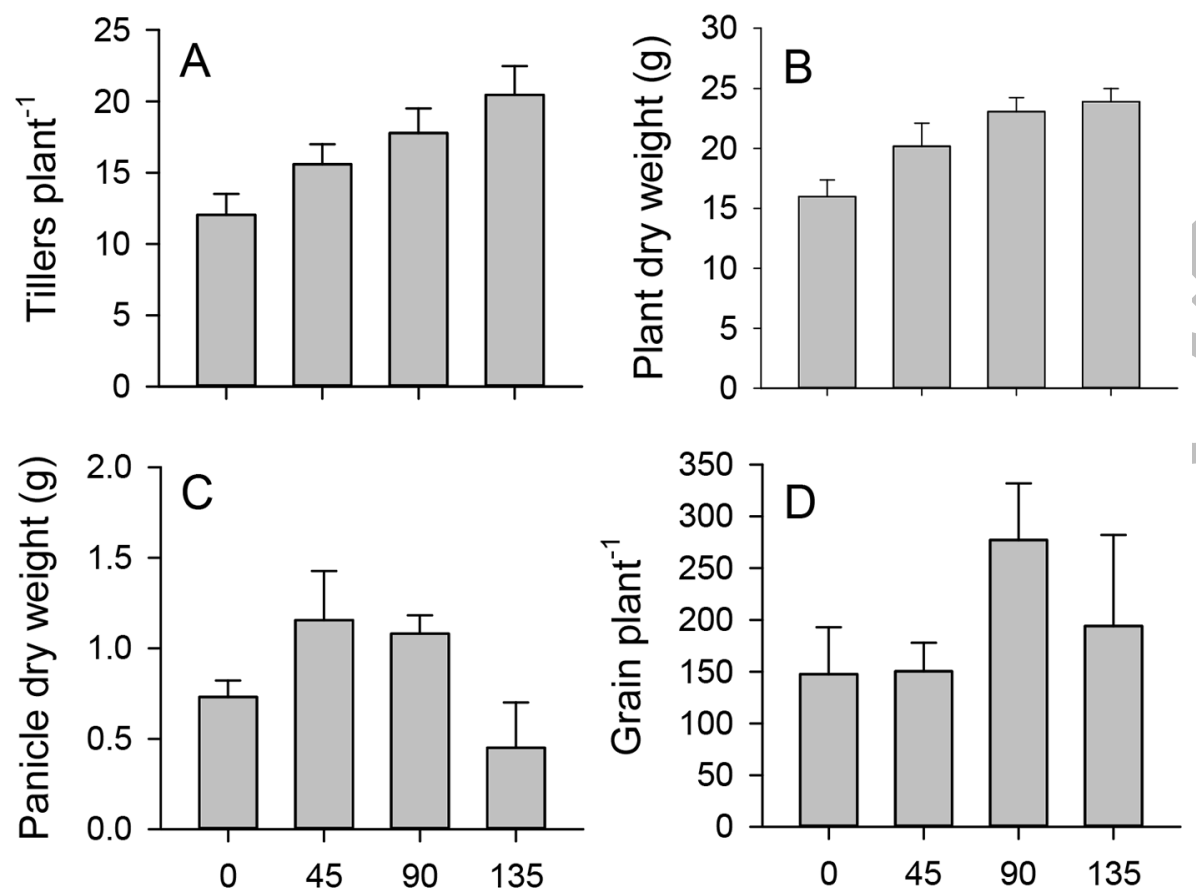

\section{Nitrogen applied $\left(\mathrm{Kg} \mathrm{ha}^{-1}\right)$}

Fig. 1. The number of tillers (A), plant dry weight (B), panicle dry weight $(\mathbf{C})$ and grain number (D) per plant under four nitrogen application rates in the main plots of the field experiment at the time of black bug invasion. The factor 'variety' (subplots) had no significant effect on these plant parameters and is not included in the figure (standard errors are indicated, $\mathrm{N}=4$ ).

remain attached to the plants between the tillers during sampling (Ferrer \& Shepard 1987). Once the insects had been removed from the plants, the plants were processed by counting the numbers of tillers, the number of panicles and the number of filled and non-filled grain (Fig. 1). The plants were separated into shoots with roots, and panicles, and were dried for 7 days at $60{ }^{\circ} \mathrm{C}$ in a forced draught oven. After drying, the plant materials were weighed on a precision balance.

We also conducted sweep netting to estimate black bug densities on 8 and 18 November. We sampled each subplot of the LTCCE using 10 sweeps of standard entomological nets during the late afternoon. All insects from the nets were stored in $90 \%$ ethanol and the captures were identified recording the nymph stages of each black bug. 

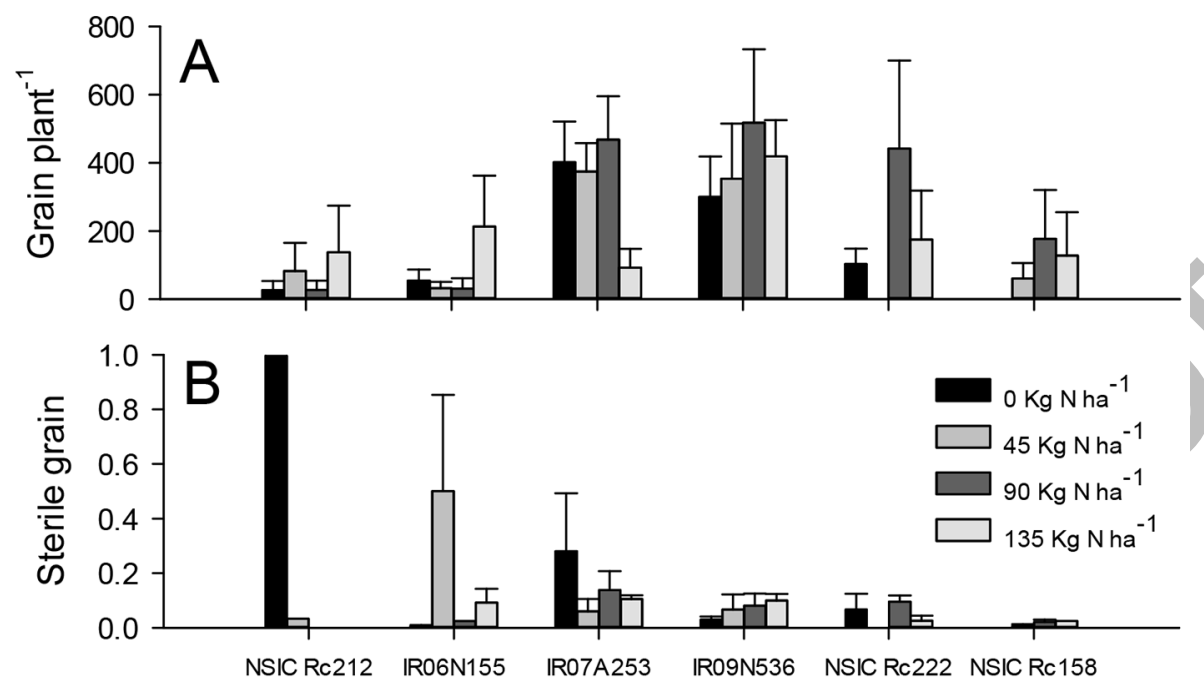

\section{Rice variety}

Fig. 2. The number of grain per plant (A) and the proportion of grain that was empty or sterile (damaged by black bug) (B) during the field experiment. Results are for six varieties (subplots) under four nitrogen application rates (main plots). Varieties are arranged in order of decreasing damage (left to right). Grain number is indicated as an indicator of plant development because grain/panicle weights may have been affected by black bugs at the time of sampling (standard errors are indicated, $\mathrm{N}=4$ ).

\subsection{Data analysis}

We conducted split-plot general linear models (GLM) to examine the effects of nitrogen, variety and their interactions on rice tiller number, plant biomass, panicle biomass, the number of grains per plant, and the proportion of grain that was unfilled (sterile and whiteheads) per plant. Similarly we conducted two separate split-plot GLMs and examined linear contrasts for egg mass densities and free-living stages of the black bug as estimated from destructively sampled plants. We plotted residuals after all analyses. Where the residuals were not normal or homogenous we used a series of data transformations before repeating the analyses, where these did not improve homogeneity of residuals the data were ranked. Where variety had no effect, we only present results for the main plots in our results figures (Fig. 2).

We used multivariate GLM to examine black bug populations from pulled plants. The dependent variables were the numbers of adult black bugs, nymphs 1 , nymphs 2 and egg masses per plant. The model examined the effects of nitrogen, rice variety and their interaction on black bug densities (number per plant) removing the effects 
of blocks. We also included plot rows as a covariate because of a clear light gradient across the experiment, however, the factor 'rows' had no significant effect and was subsequently removed from the analysis. Analyses were conducted with degrees of freedom and error terms for a split-plot design with nitrogen as the main plot and variety as subplots. Linear contrasts for nitrogen were examined.

The total numbers of black bugs captured in sweep nets during the two sampling periods were examined using repeated measures GLM for a split-plot design. Because only few nymphs were captured during the first sweep net sampling, we examined nymph development only for the second sample. Numbers of adults and nymphs (of each instar) were analyzed using split-plot multivariate GLM removing the effects of rows and blocks. Contrasts for nitrogen were also examined. The data was ranked before analysis (see above). We conducted a similar analysis using the proportion of nymphs of each instar. In this case, the data was arcsine transformed and residuals were found to be normal and homogenous. Because variety had no effect, we only present results for the main plots in our results figures.

We conducted multiple regression analyses with backward elimination to determine the best predictors of adult and egg densities with tiller numbers, plant biomass, panicle biomass and grain number as independent variables. Residuals were plotted following analyses and were normal and homogeneous. We examined the relation between captures from sampled plants and from sweep nets using Spearman's correlations.

\section{$3 \quad$ Results}

\subsection{Rice responses to nitrogen}

Tiller number $\left(\mathrm{F}_{3,9}=6.789, \mathrm{P}=0.011\right.$, contrast $\left.<0.001\right)$ and plant biomass $\left(\mathrm{F}_{3,9}=\right.$ $4.409, \mathrm{P}=0.036$, contrast $<0.001)$ increased under increasing nitrogen levels. There was no difference between panicle weights $\left(\mathrm{F}_{3,9}=2.416, \mathrm{P}=0.134\right)$ or grain number $\left(\mathrm{F}_{3,9}=0.422, \mathrm{P}=0.742\right)$ under different levels of nitrogen at the time of field monitoring. The proportion of sterile grain (whiteheads) tended to decrease under higher nitrogen regimes as indicated by a significant linear contrast $\left(\mathrm{F}_{3,9}=\right.$ $2.649, \mathrm{P}=0113$, contrast $=0.040$ ). There was no variety effect on tiller number, plant biomass, grain number and grain sterility $\left(1.519 \geq \mathrm{F}_{5,36} \geq 0.262\right)$, however, varieties IR09N536 and IR07A253 had heavier panicles than the remaining four varieties $\left(\mathrm{F}_{5,36}=9.822, \mathrm{P}<0.001\right)$. All interactions were non-significant $(1.653 \geq$ $\left.\mathrm{F}_{15,36} \geq 0.268\right)$ except for grain sterility $\left(\mathrm{F}_{3,9}=2.295, \mathrm{P}=0.021\right)$ because of high sterility in NSIC Rc212 and IR06N155 under low nitrogen but low sterility, equal to the other varieties, under higher nitrogen. Sterility was most prevalent in block $4\left(\mathrm{~F}_{3,9}=4.107, \mathrm{P}=0.043\right)$. 


\subsection{Spatial dynamics of black bugs in the field plots}

Total black bug densities were not significantly affected by nitrogen $\left(\mathrm{F}_{3,9}=1.779\right.$, $\mathrm{P}=0.221)$, variety $\left(\mathrm{F}_{5,36}=0.181, \mathrm{P}=0.966\right)$ or their interaction $\left(\mathrm{F}_{15,36}=0.820\right.$, $\mathrm{P}=0.650$ ), however, there was a significant linear contrast with increasing nitrogen $(\mathrm{P}=0.006)$. Similarly, the number of egg masses per plant was not significantly affected by nitrogen treatment $\left(\mathrm{F}_{3,9}=1.722, \mathrm{P}=0.232\right)$, variety $\left(\mathrm{F}_{5,36}=0.873\right.$, $\mathrm{P}=0.522)$ or their interaction $\left(\mathrm{F}_{15,36}=0.430, \mathrm{P}=0.959\right)$ as main effects, but did show a significant linear contrast for nitrogen $(\mathrm{P}=0.002)$. There were also lower numbers of egg masses in blocks 2 and 3 than in block $4\left(\mathrm{~F}_{3,9}=3.767, \mathrm{P}=0.053\right)$. There were an average of $36 \pm 3(\mathrm{SEM})$ eggs per egg masse (range $=16-57)$. Egg mass size was not affected by nitrogen level $\left(\mathrm{F}_{3,16}=0.425, \mathrm{P}=0.738\right.$, contrast $\left.=0.381\right)$.

Our multivariate analyses indicated that nitrogen levels did not significantly affect adult $\left(\mathrm{F}_{3,9}=2.996, \mathrm{P}=0.088\right)$, nymph $1\left(\mathrm{~F}_{3,9}=1.259, \mathrm{P}=0.273\right)$, nymph $2\left(\mathrm{~F}_{3,9}=\right.$ $1.071, \mathrm{P}=0.409)$ or egg mass $\left(\mathrm{F}_{3,9}=2.317, \mathrm{P}=0.144\right)$ densities, however, as with the univariate analysis, there were significant linear contrasts for adults $(\mathrm{P}=0.016)$ and egg masses $(P=0.002)$. There were no significant variety $\left(1.665 \geq F_{15,36} \geq 0.391\right)$ or (nitrogen $\times$ variety) interactions $\left(0.757 \geq F_{15,36} \geq 0.384\right)$ for any life stage.

Linear multiple regression indicated plant biomass as the best predictor of adult black bug densities $\left(\mathrm{R}^{2}=0.148, \mathrm{~F}_{1,94}=16.149, \mathrm{P}<0.001\right)$ and grain and tiller numbers as the best predictors of egg mass densities $\left(\mathrm{R}^{2}=151, \mathrm{~F}_{2,94}=8.202, \mathrm{P}=0.001\right)$. The proportion of empty grains per panicle were significantly correlated with adult black bug densities (Spearman's rank $=0.467, \mathrm{df}=22, \mathrm{P}=0.026$ ).

\subsection{Black bug distribution and development assessed by sweep netting}

Total black bug densities increased between the two sweep net sampling periods (Time: $\left.\lambda_{1,69}=0.826, \mathrm{~F}_{1,69}=14.516, \mathrm{P}<0.001\right)$ during which time nymphs began to emerge. This increase was not affected by nitrogen level (Time $\times$ nitrogen: $\lambda_{3,69}=0.927, \mathrm{~F}_{\mathrm{s}, 69}=$ $1.807, \mathrm{P}=0.154$ ) or variety (Time $\times$ variety: $\lambda_{3,69}=0.937, \mathrm{~F}_{\mathrm{s}, 69}=0.929, \mathrm{P}=0.468$ ), however, there was a significant (time $\times$ block) interaction $\left(\lambda_{3,69}=0.789, \mathrm{~F}_{\mathrm{s}, 69}=6.151\right.$, $\mathrm{P}=0.001$ ) as densities increased in block 4 , but remained relatively stable in the other blocks. All between subject effects were not significant $(\mathrm{P}>0.05$, linear contrast for nitrogen $=0.060)$. Block $\left(2.879 \geq F_{3,9} \geq 0.172\right)$, nitrogen level $\left(1.575 \geq F_{3,9} \geq 0.057\right)$, variety ( $\left.2.047 \geq F_{5,36} \geq 0.393\right)$, and (nitrogen $\times$ variety) interactions $\left(0.936 \geq F 1_{5,36}\right.$ $\geq 0.356$ ) had no significant effects on any life stages as captured in the second sweep net sampling, however, there were significant linear contrasts as densities of nymphs 3 $(\mathrm{P}=0.003)$ and nymphs $4(\mathrm{P}=0.009)$ increased under increasing nitrogen. Analyses of development stages also indicated a significant linear decrease in the proportion of first instars among the nymph populations with increasing nitrogen levels $\left(\mathrm{F}_{3,9}=0.530\right.$, $\mathrm{P}=0.673$, contrast $=0.020)($ Fig. 5). All other factors were non-significant $(\mathrm{P}>0.05)$. Densities of free-living black bugs as estimated from pulled plants and sweep nets were correlated (Spearman's rank $=0.413, \mathrm{df}=24, \mathrm{P}=0.045$ ). 


\section{Discussion}

The localized outbreak that we describe here is typical of previously reported early dry season outbreaks for other black bug species. Farmers in Palawan reported to Redonda et al. (2007) that outbreaks of $S$. coarctata were more common in the dry season between December and February. The LTCCE at IRRI was vulnerable to outbreak at the time of this study because the plots represented a standing crop of rice in a landscape dominated by rice stubble in harvested fields. Though not a perfect Latin Square, the LTCCE plots allowed us to examine the influence of row and block positions on the populations of black bug. Plots at the centre of field had the lowest densities of adult black bugs, whereas plots in block 4 had the highest numbers of adults. This indicates that the adults arrived to the site from other rice fields in the regions (i.e., they had not developed from eggs in the plots). Furthermore, adult dispersal to the site was predominantly from a north easterly direction (into block 4) from where the largest extensions of recently harvested rice fields were located. This further confirms the contribution of asynchronous cropping to this outbreak. The low number of replicates in the study and high variability in populations between plots often obscured treatment effects, however, densities of several black bug life stages showed strong linear trends with increasing nitrogen.

Our analyses indicate that adult black bugs were less selective of rice plants based on nitrogen applications, but that egg-laying was predominantly associated with higher nitrogen plots. The varieties used in the experiment showed no resistance to black bugs: Colonization and egg-laying by the bugs was similar among the six varieties (subplots). We limited our study to the early stages in the outbreak to avoid confounding the effects of later pesticide applications to the site, this also avoided confusing the two generations of adults (invaders to the site and their progeny from the site) and provided a better basis for detecting nitrogen effects on developing nymphs. By the time of our second sampling, third instar nymphs predominantly occurred in the high nitrogen plots ( 90 and $135 \mathrm{Kg} \mathrm{N} \mathrm{ha}^{-1}$ ) and fourth instars were only recorded from high nitrogen plots.

Although insect herbivores from a range of feeding guilds demonstrate higher preferences and increased fitness on high quality host plants (such as those grown under high light conditions with sufficient water and nutrients: Butler et al. 2012, Han et al. 2014, 2015, Hu et al. 2016, Rashid et al. 2016), plant-sucking bugs are predicted to show more marked responses (higher abundance and fitness) to plant nitrogen levels than other feeding guilds because they directly access assimilated nutrients available in the phloem (Mattson 1980, Price 1991, Cornelissen \& Fernandes 2008, Chen et al. 2010). However, based on a recent meta-analysis, Gripenberg et al. (2010) indicated that insect herbivores with broad diets were less selective of oviposition sites. Black bugs are considered poor dispersers (Nakasuji et al. 1965), which together with a relatively broad diet, suggests that these should exhibit weak preference-performance correlations. Our results suggest that adult black bugs alighted on rice plants as these were encountered, resulting in higher numbers of adults at the edges of the experimental field and on larger plants. The densities of egg masses were also highest at the edges of the experiments, however, 
egg mass densities showed a stronger response to nitrogen levels compared to adult densities, indicating that the adults laid more eggs in the high nitrogen plots. In an analysis of spatial patterns of Scotinophara lurida (Burmeister), Kim et al. (2007) also found that adult black bugs were randomly distributed within rice plots. However, even among their homogenous rice plots, Kim et al. (2007) noted nymphs and young adults became more aggregated over time and aggregation patterns were carried over to subsequent generations.

Our results also suggest that nymphs that emerged from eggs in high nitrogen plots developed faster than nymphs in low nitrogen plots. At the time when we conducted or first sampling, second instars occurred in all plots, but first instar nymphs occurred predominantly in the high nitrogen plots. This indicated that females continued to lay eggs in high nitrogen plots over a longer time period than in the low nitrogen plots (Fig. 3). Although females may also have initiated oviposition earlier in the high nitrogen plots, the presence of second instars in all plots suggests that this would only have had a minor influence on the demographic patterns observed among the plots. Bioassays with nymphs on plants under different nitrogen regimes in laboratory arenas or field cages would help clarify any effects of nitrogen on nymph development. Nevertheless, our results suggest better performance by nymphs under high nitrogen and indicate that populations with more advanced nymph development occur under high nitrogen. The black bug's life-history strategy therefore supports the preference-performance hypothesis, which holds that adults choose the best sites for oviposition based on the likelihood of maximizing the fitness of their progeny. However, weak responses by adults to variability in host quality, suggests that the scale of our experiment may have influenced oviposition as adults could disperse relatively short distances within the experimental area to find better hosts.

From a series of screening studies conducted in Palawan (Philippines) with S. coarctata, Heinrichs et al. (1987) reported two varieties (IR10781-75-5-2-2 and IR13149-71-3-2) with apparent tolerance to rice bug attack. Tolerance is the ability of plants to compensate for herbivore damage. Unlike resistance, tolerance does not result in selective pressure on the herbivore towards adaptation (Horgan 2017). Our results indicate that different varieties in the LTCCE matured at different times. Black bugs laid more eggs on varieties with more advanced development as indicated by a relation between grain number and the density of egg masses. However, this was not reflected in any preferences by black bugs for particular varieties, but simply a response to physiological differences between plants at the time of sampling. Tolerance is related to resource availability. Rice plants under high nitrogen are often more tolerant of herbivore damage (Horgan et al. 2016a). Our results suggest that plants under high nitrogen were able to better tolerate the black bug damage, producing a higher proportion of filled grain. Under low nitrogen, despite often lower densities of black bugs, whiteheads and grain sterility were more prevalent.

Outbreaks of black bug can be avoided through synchronous cropping and strict fallow periods. Given the current lack of relevant scientific studies and increasing importance of black bugs as rice pests, further research into black bug biology and management should be encouraged. Ours is the first field-scale study on the effects of 


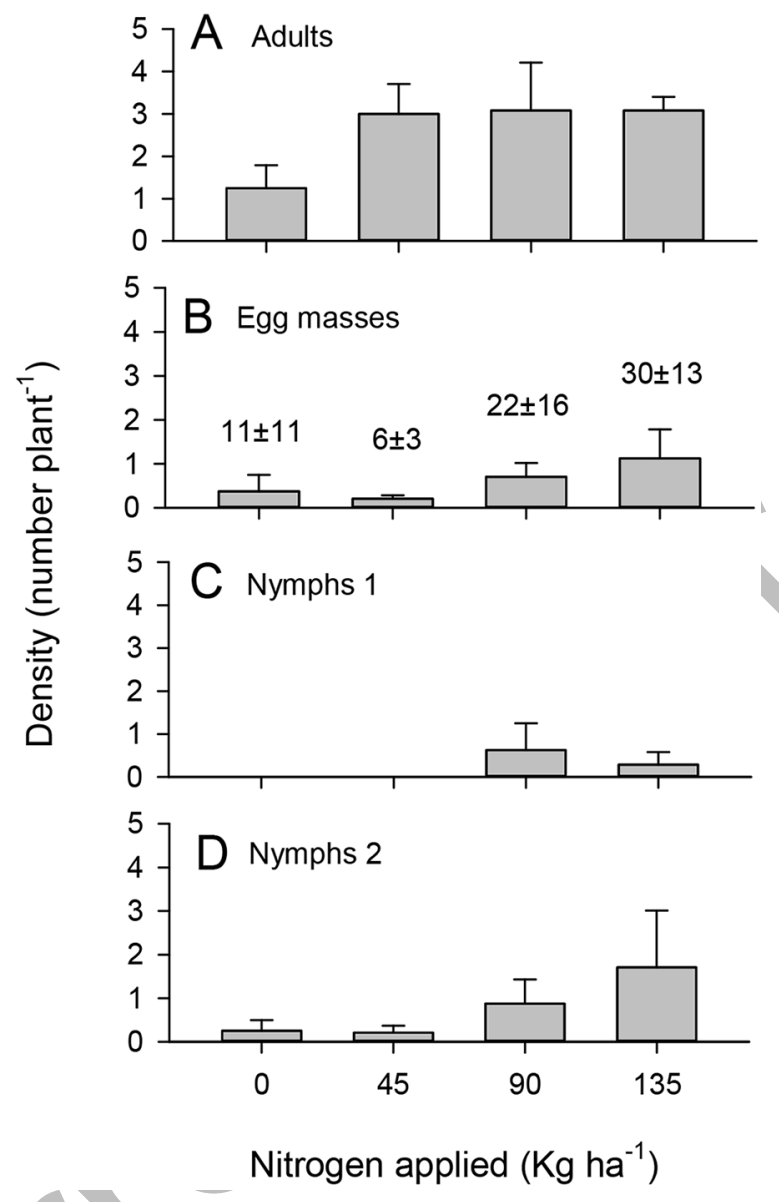

Fig. 3. Black bug densities as estimated from sampled plants. Densities of adults (A), egg masses (B), nymphs 1 (C) and nymphs 2 (D) are indicated. The numbers of eggs per plant are also presented (numbers in B). Data are averages (+ standard errors, $N=4$ ) for the main plots under four nitrogen regimes. The factor 'variety' (subplots) had no significant effect and is not included in the figure. Adults are from the first generation only, eggs and larvae are from the second generation. 


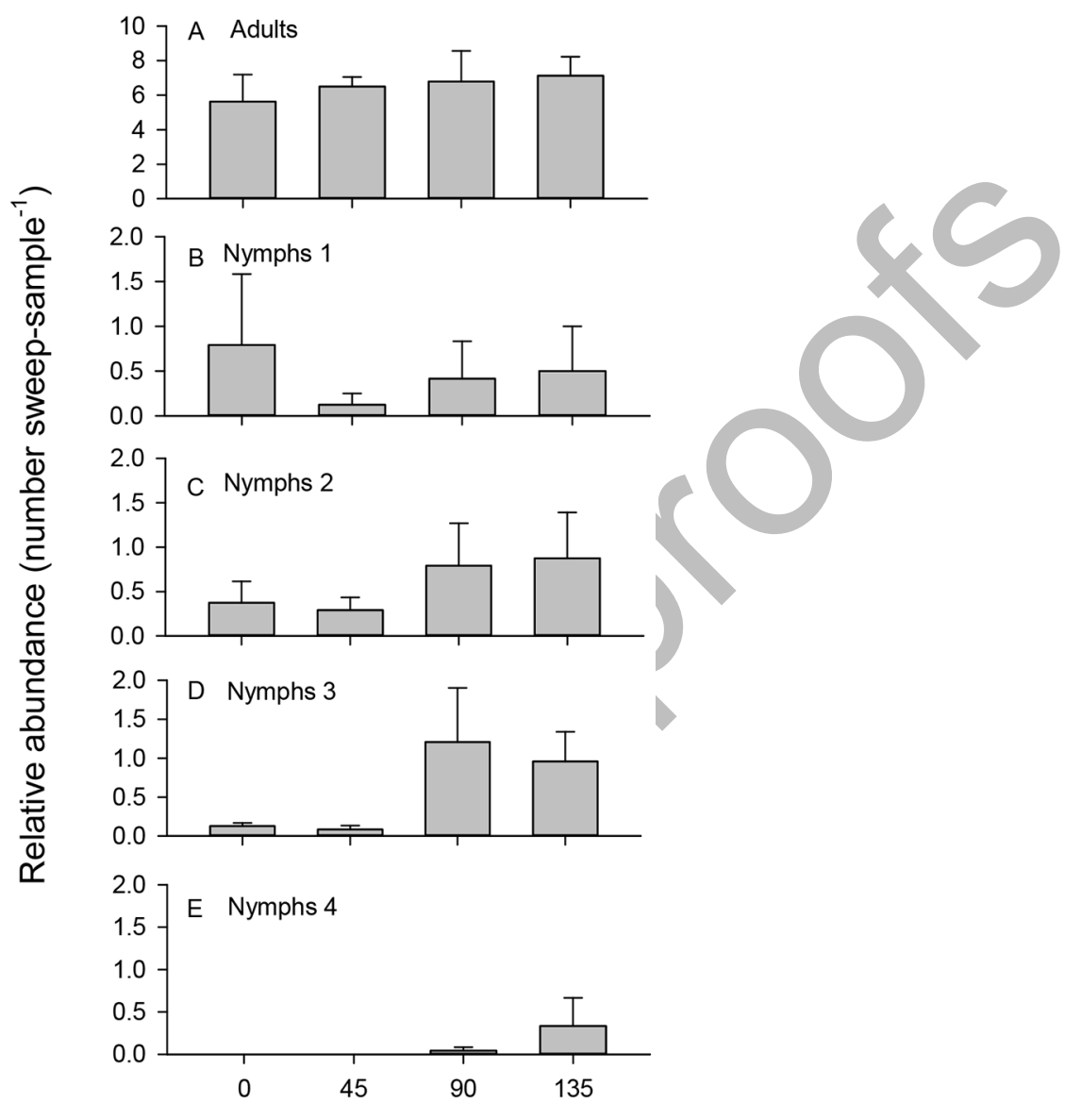

Nitrogen applied $\left(\mathrm{Kg} \mathrm{ha}^{-1}\right)$

Fig. 4. Black bug abundance estimated from sweep nets. The relative abundance of adults $(\mathbf{A})$, nymphs 1 (B), nymphs 2 (C), nymphs 3 (D) and nymphs $4(\mathrm{E})$ are indicated. Data are averages (+ standard errors, $\mathrm{N}=4$ ) for the main plots under four nitrogen regimes. The factor 'variety' (subplots) had no significant effect and is not included in the figure. Adults are from the first generation only and larvae are from the second generation. 


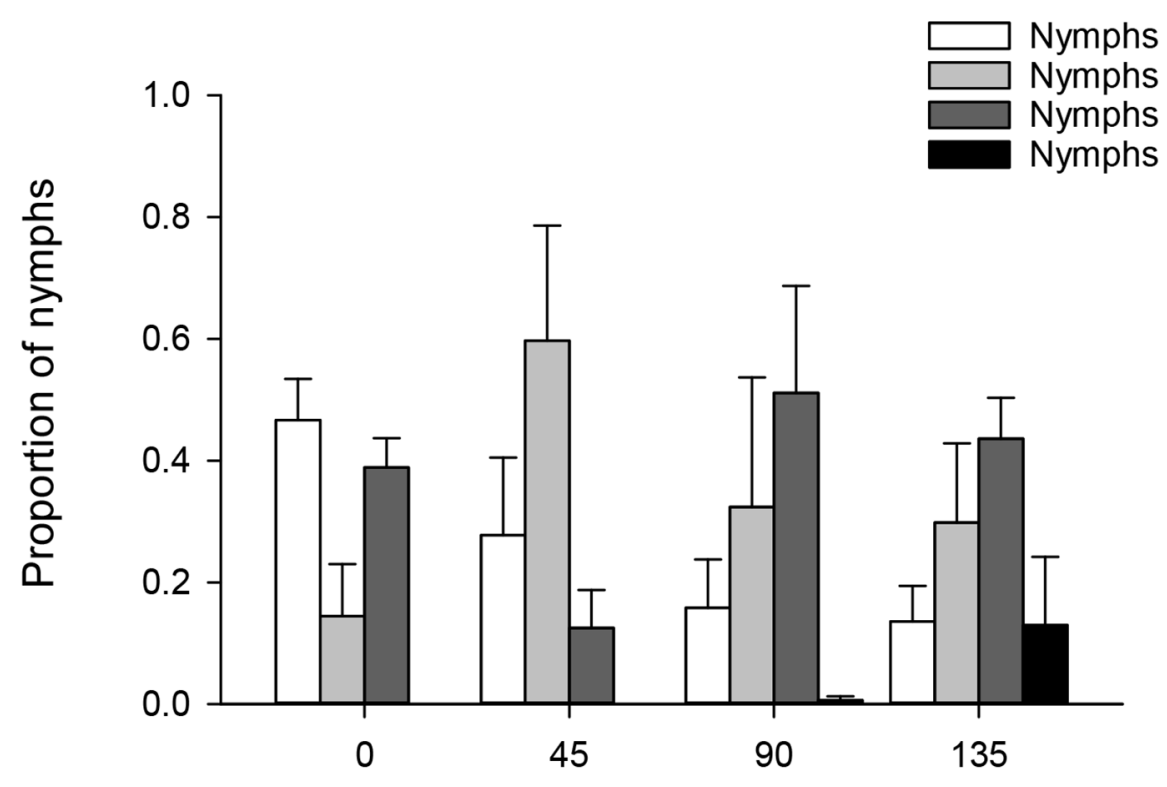

\section{Nitrogen applied $\left(\mathrm{Kg} \mathrm{ha}^{-1}\right)$}

Fig. 5. Developmental stages of nymphs from sweep netting of rice plots under four nitrogen treatments. The proportions of nymphs at instars 1 (open), 2 (light grey), 3 (dark grey) and 4 (black) are presented. Standard errors are indicated ( $\mathrm{N}=4$ main plots). Variety (subplots) had no significant effect and is not shown.

fertilizers on black bugs. The results indicate a pathway to invasion and population build-up in black bugs based on adult dispersal and oviposition preferences. Because of active migration by black bugs between rice-growing regions and especially in response to moonlight and light pollution (Ferrer \& Shepard 1987, Cuaterno 2007), larger-scale (landscape or regional) studies would be useful.

Acknowledgements: The authors thank Leigh Vial and Theodoro 'Jun' Correa for information regarding management of the experimental plots, Alberto Naredo, Rayuel Quintana, Vincent Vertudes and Ellen Genil for technical and administrative support. Eduardo Crisol-Martínez and an anonymous reviewer for helpful comments on the manuscript. This research was funded by the Global Rice Science Partnership (GRiSP) and the Faculty of Science of the University of Technology Sydney. 


\section{References}

Barrion, A.T., Joshi, R.C., Barrion-Dupo, A.L.A. \& Sebastian, L.S. (2007): Systematics of the Philippine rice black bug, Scotinophara Stål (Hemiptera: Pentatomidae). - In: Joshi, R.C., Barrion, A.T. \& Sebastian, L.S. (eds.): Rice black bugs: taxonomy, ecology, and management of invasive species. - Philippine Rice Research Institute, Nueva Ecija, Philippines, pp. 3-180.

Butler, J., Garratt, M.P.G. \& Leather, S.R. (2012): Fertilisers and insect herbivores: a meta-analysis. Annals of Applied Biology 161: 223-233.

Chen, Y., Olson, D.M. \& Ruberson, J.R. (2010): Effects of nitrogen fertilization on tritrophic interactions. - Arthropod-Plant Interactions 4: 81-94.

Cornelissen, T. \& Fernandes, G.W. (2008): Size does matter: variation in herbivory between and within plants and the plant vigor hypothesis. - Oikos 117: 1121-1130.

Crisol, E., Almazan, M.L.P., Jones, P.W. \& Horgan, F.G. (2013): Planthopper-rice interactions: unequal stresses on pureline and hybrid rice under similar experimental conditions. - Entomologia Experimentalis et Applicata 147: 18-42.

Cuaterno, W.R. (2007): Current status of rice black bug and its management in the Philippines. - In: Joshi, R.C., Barrion, A.T. \& Sebastian, L.S. (eds.): Rice black bugs: taxonomy, ecology, and management of invasive species. - Philippine Rice Research Institute, Nueva Ecija, Philippines, pp. 653-660.

De Kraker, J., Rabbinge, R., van Huis, A., van Lenteren, J.C. \& Heong, K.L. (2000): Impact of nitrogenous-fertilization on the population dynamics and natural control of rice leaffolders (Lep.: Pyralidae). - International Journal of Pest Management 46: 225-235.

Dobermann, A., Dawe, D., Roetter, R.P. \& Cassman, K.G. (2000): Reversal of rice yield decline in a long-term continuous cropping experiment. - Agronomy Journal 92: 633-643.

Ferrer, E.R. \& Shepard, B.M. (1987): Sampling Malayan black bugs (Heteroptera: Pentatomidae) in rice. - Environmental Entomology 16: 259-263.

Gripenberg, S., Mayhew, P.J., Parnell, M. \& Roslin, T. (2010): A meta-analysis of preference-performance relationships in phytophagous insects. - Ecology Letters 13: 383-393.

Han, P., Lavoir, A.V., Le Bot, J., Amiens-Desneux, E. \& Desneux, N. (2014): Nitrogen and water availability to tomato plants triggers bottom-up effects on the leafminer Tuta absoluta. - Scientific Reports 4: 4455.

Han, P., Dong, Y.C., Lavoir, A.V., Adamowicz, S., Bearez, P., Wajnberg, E. \& Desneux, N. (2015): Effect of plant nitrogen and water status on the foraging behaviour and fitness of an omnivorous arthropod. - Ecology and Evolution 5: 5468-5477.

Heinrichs, E.A., Domingo, I.T. \& Castillo, E.H. (1987): Resistance and yield responses of rice cultivars to the black bug Scotinophara coarctata (F.) (Hemiptera: Pentatomidae). - Journal of Plant Protection in the Tropics 4: 55-64.

Horgan, F.G (2017): Integrated pest management for sustainable rice cultivation: a holistic approach. In: Sasaki, T. (ed.): Achieving sustainable cultivation of rice. - Burleigh Dodds Science, Oxford, UK.

Horgan, F.G. \& Crisol, E. (2013): Hybrid rice and insect herbivores in Asia. - Entomologia Experimentalis et Applicata 148: 1-19.

Horgan, F.G., Crisol-Martínez, E., Almazan, M.L.P., Romena, A., Ramal, A.F., Ferrater, J.B. \& Bernal, C.C. (2016a): Susceptibility and tolerance in hybrid and pure-line rice varieties to herbivore attack: biomass partitioning and resource-based compensation in response to damage. Annals of Applied Biology 169: 200-213.

Horgan, F.G., Srinivasan, T.S., Naik, B.S., Ramal, A.F., Bernal, C.C. \& Almazan, M.L.P. (2016b): Effects of nitrogen on egg-laying inhibition and ovicidal response in planthopper-resistant rice varieties. - Crop Protection 89: 223-230.

Hu, X.F., Cheng, C., Luo, F., Chang, Y.Y., Teng, Q., Men, D.Y., Liu, L. \& Yang, M.Y. (2016): Effects of different fertilization practices on the incidence of rice pests and diseases: A three-year case study in Shanghai, in subtropical southeastern China. - Field Crops Research 196: 33-50. 
Joshi, R.C., Barrion, A.T. \& Sebastian, L.S. (2007) Rice black bugs: taxonomy, ecology, and management of invasive species. - Philippine Rice Research Institute, Nueva Ecija, Philippines, p 793.

Kim, H., Kim, S.T., Jung, M.P. \& Lee, J.H. (2007): Spatio-temporal dynamics of Scotinophara lurida (Hemiptera: Pentatomidae) in rice fields. - Ecological Research 22: 204-213.

Lu, Z., Villareal, S., Yu, X., Heong, K.L. \& Cui, H. (2006): Biodiversity and dynamics of planthoppers and their natural enemies in rice fields with different nitrogen regimes. - Rice Science 13: 218-226.

Mattson, W.J. (1980): Herbivory in relation to plant nitrogen content. - Annual Review of Ecology and Systematics 11: 119-161.

Morrill, W.L., Shepard, B.M., Rida, G.S. \& Parducho, M. (1995): Damage by the Malayan black bug (Heteroptera: Pentatomidae) in rice. - Journal of Economic Entomology 88: 1466-1468.

Nakasuji, F., Hokyo, N. \& Kiritani, K. (1965): Spatial distribution of three plant bugs in relation to their behavior. - Researches in Population Ecology 7: 99-108.

Price, P.W. (1991): The plant vigor hypothesis and herbivore attack. - Oikos 62: 244-251.

Rashid, M.M., Jahan, M. \& Islam, K.S. (2016): Impact of nitrogen, phosphorus and potassium on brown planthopper and tolerance of its host rice plant. - Rice Science 23: 119-131.

Redondo, G.O., Launio, C.C. \& Manalili, R.G. (2007): Farmer's knowledge, perceptions, and management practices on rice black bug. - In: Joshi, R.C., Barrion, A.T. \& Sebastian, L.S. (eds.): Rice black bugs: taxonomy, ecology, and management of invasive species. - Philippine Rice Research Institute, Nueva Ecija, Philippines, pp. 287-306.

Rubia-Sanchez, E.G., Suzuki Y., Miyamoto, K. \& Watanabe, T. (1999): The potential for compensation of the effects of the brown planthopper Nilaparvata lugens Stål (Homoptera: Delphacidae) feeding on rice. - Crop Protection 18: 39-45.

Shepard, B.M., Arida, G.S., Justo, H.D. \& Ooi, P.A.C. (2007): Biological control of the rice black bug. - In: Joshi, R.C., Barrion, A.T. \& Sebastian, L.S. (eds.): Rice black bugs: taxonomy, ecology, and management of invasive species. - Philippine Rice Research Institute, Nueva Ecija, Philippines, pp. 317-328.

Vandermeer, J., van Noordwijk, M., Anderson, J., Ong, C. \& Perfecto, I. (1998): Global change and multispecies agroecosystems: concepts and issues. - Agriculture, Ecosystems and Environment 67: $1-22$.

Manuscript received: 1 March 2017

Revision required: 23 June 2017

Revised version received: 23 June 2017

Accepted: 26 June 2017 